\title{
Sleep problems in excessive technology use among adolescent: a systemic review and meta-analysis
}

\author{
Xi Mei ${ }^{1,2^{*}}$, Qi Zhou ${ }^{1,2}$, Xingxing Li ${ }^{1,2}$, Pan Jing ${ }^{2}$, Xiaojia Wang ${ }^{2}$ and Zhenyu $\mathrm{Hu}^{1,2}$
}

\begin{abstract}
Background: Inadequate sleep quantity and quality is a public health concern with an array of detrimental health outcomes. Portable technological devices have become a ubiquitous part of adolescents' lives and may affect their sleep duration and quality. The purpose of this study was to summarize published analyses of various technology uses and sleep outcomes and to examine whether there is an association between excessive technology use (ETU) and poor sleep outcomes in adolescents.

Method: We conduct a systematic review and meta-analysis. Pubmed, Embase, Science Direct, Google Scholar, Cochrane Library were used. Inclusion and exclusion criteria were performed. Only original research papers published from 1999 to 2018 and offcially reviewed by peers were included for analysis. We used the Review Manager 5.3 software for statistical analysis.

Results: Nineteen studies were included, and their quality was assessed. These studies involved 253,904 adolescents (mean [SD] age, 14.82 [0.83] years; $51.1 \%$ male). There was a strong and consistent association between ETU and sleep problems (odds ratio [OR], 1.33; 95\% Cl, 1.24-1.43) $\left(P<0.00001, \mathrm{I}^{2}=96 \%\right.$ ), reduced sleep duration (SMD, $-0.25 ; 95 \% \mathrm{Cl},-0.37-0.12)\left(P<0.00001, \mathrm{I}^{2}=81 \%\right)$, and prolonged sleep onset latency $(\mathrm{OR}, 0.16 ; 95 \% \mathrm{Cl},-0.02-0.34)\left(P=0.05, \mathrm{I}^{2}=66 \%\right)$.

Conclusions: ETU has a significant effect on sleep duration in adolescents over 14 years of age, prolong the $\mathrm{SOL}$ of adolescents, and may lead to several sleep problems. Interventions must be developed to raise awareness of the potential health hazard to improve sleep hygiene through an integrated approach involving teachers, health care professionals, and parents.
\end{abstract}

Keywords: Excessive technology use, Sleep problems, Adolescents, Meta-analysis

\section{Background}

Sleep plays an important role in the growth of young people. The problem of sleep affects human cognition and social function, and is also a warning signal for a variety of diseases. Sleep disorders negatively affects several domains including school performance, mood regulation, cognitive process, and general health in adolescents (Dahl \& Lewin, 2002; Gruber et al., 2012; Fredriksen et al., 2004; Wolfson \& Carskadon, 1998). The USA National Sleep Foundation (NSF, 2006) recommends that adolescents sleep for no less

\footnotetext{
* Correspondence: meixi18401856@163.com

${ }^{1}$ Ningbo Key Laboratory of Sleep Medicine, Zhuangyu South Road No.1,

Zhenhai District, Ningbo City 315201, Zhejiang Province, China

${ }^{2}$ Ningbo Kangning Hospital, Ningbo City 315201, Zhejiang Province, China
}

than 9 hours a day (National Sleep Foundation, 2006), but in the USA, 75\% of those 17 to 18 years old report insufficient sleep, and young people in other developed countries have the same phenomenon (National Sleep Foundation, 2014).

Teenagers now have multiple electronic devices such as smart phones and ipad. The daily watch on the screen has increased significantly. Excessive technology use (ETU) may contribute to the adolescent insufficient sleep. Previous study have found that sleep reduction appears to be aggravated by excessive use of technology devices such as TV viewing (Tynjala et al., 1993), internet use (Yen et al., 2008), video gaming (Weaver et al., 2010; Rehbein et al., 2010) and mobile telephone use

(c) The Author(s). 2018 Open Access This article is distributed under the terms of the Creative Commons Attribution 4.0 International License (http://creativecommons.org/licenses/by/4.0/), which permits unrestricted use, distribution, and 
(Van den Bulck, 2007; Munezawa et al., 2011). ETU have been found to be associated with reduced sleep duration (Tynjala et al., 1993), delayed sleep onset latency (Tynjala et al., 1993; Weaver et al., 2010) and increased other sleep problems (Rehbein et al., 2010; Munezawa et al., 2011).

ETU in teenagers has been a hot spot of research for decades. A large number of academic literatures have reported related studies. However, the association between ETU and poor sleep outcomes has been underexplored, because the speed of technological devices developing has outpaced the research capabilities. In the current study, we present a systematic review to quantify the influence of ETU on sleep outcomes in a meta-analysis. Compared to previous study (Carter et al., 2016), we make a further exploration of sleep duration, sleep onset latency, as well as include several new related articles.

\section{Method}

\section{Databases online}

Pubmed, Embase, Science Direct, Google Scholar, Cochrane Library were used. We conducted extensive searches for studies published from 1999 using the terms "excessive Internet/technology use" or "problematic Internet/technology use" or "pathological Internet/technology use" or "Internet addiction" or "excessive computer/technology use" or "Internet gaming" or "computer gaming" or "Internet gaming addiction" combined with the terms "insomnia" or "sleep problems" or "sleep quality" or "sleep disorders" or "sleep disturbance" or "sleep deprivation". The year 1999 was chosen as the starting year for the search because that is when active empirical inquiry into the psychological factors affecting Internet addiction first began.

\section{Study selection}

This study was conducted following Preferred Reporting Items for Systematic Reviews and Meta-analyses (PRISMA) guidelines. After completing the search on the electronic databases, titles and abstracts of the identified articles were assessed for their suitability to be included in this research. Studies were included if they (1) were epidemiological studies of adolescents of school age between 11 and 20 years with appropriate study designs; (2) were cross-sectional, case-control and cohort studies that examined the relationship between ETU or problematic internet use and sleep problems including insomnia and poor sleep quality; (3) provided information of ETU and sleep outcomes in the shape of quantized data.

\section{Exclusion criteria}

Studies were excluded if they 1) did not provide sufficient information to calculate the aggregate prevalence and odds ratio (OR); 2) did not provide a specific definition or criteria for ETU or problematic internet use; 3 ) the authors did not respond to provide further information upon request including the psychiatric co-morbidity directly related to ETU (e.g. online gambling). Articles with abstracts that were written in the English language but had full texts written in non-English languages were excluded.

\section{Quality assessment}

The full texts of all relevant articles were retrieved, and their eligibility for inclusion was assessed. Two reviewers (Q.Z. and P. J.) independently assessed the methodological quality of all full-text articles, and discrepancies were resolved by a third reviewer (X.M.). We followed the guidelines in the Meta-analysis of Observational Studies in Epidemiology (MOOSE) statement for reporting (Stroup et al., 2000).

\section{Definition of poor sleep quality}

Since the Pittsburgh Sleep Quality Index (PSQI) (Buysse et al., 1989) was developed, based upon the International Statistical Classification of Disease and Related Health Problems, 10th edition (ICD-10) (World Health Organization, 1992) and the Diagnostic and Statistical Manual of Mental Disorders (DSM-V) (American Psychiatric Association, 2013) criteria for classification of insomnia, it was employed in plenty of original studies to assess insomnia and sleep disturbances. Furthermore, early awakenings, night awakenings, and long sleep onset latency were used to assess the sleep quality.

\section{Technology and internet use}

In this study, type of technology included PC, mobile phone, television, video games, and music. Internet was used for game, video, music, social communication, and study. A number of adolescents' time of usage was before sleep. In our study, we define the ETU as the problematic internet use (PIU) and excessive use of PC, cell phone, MP3 player, tablet, game console and TV as well as the technology use before sleep in bed and heavy use in daytime.

\section{Measurement of association between technology use and sleep outcomes}

Included studies measured the association between technology use and the influence on sleep using either regression slopes $(\beta)$, correlation coefficients $(r)$, or ORs. To ensure consistency in interpretation, studies that reported dichotomous data or logistic regression analyses of sleep quality and continues data of sleep duration were pooled in a meta-analysis. 


\section{Statistical analysis and heterogeneity}

All statistical analyses were performed with Review Manager 5.3 using the random-effects models for aggregate prevalence and pooled OR. Statistical heterogeneity was assessed using the $\mathrm{I}^{2}$ statistic. Dichotomous and continues data were respectively presented as OR and SMD with the associated $95 \%$ CIs, $P$ values, and $\mathrm{I}^{2}$ summary data. Heterogeneity exceeding $85 \%$ was explored using subgroup analyses. Subgroups to explore heterogeneity were classified by country.

\section{Results}

\section{Study selection}

A total of 297 studies were identified, and 67 full texts were reviewed, leading to 40 being excluded (Fig. 1). 23 studies involving 253,904 adolescent (mean [SD] age, 14.82 [0.83] years; $51.1 \%$ male) were included after

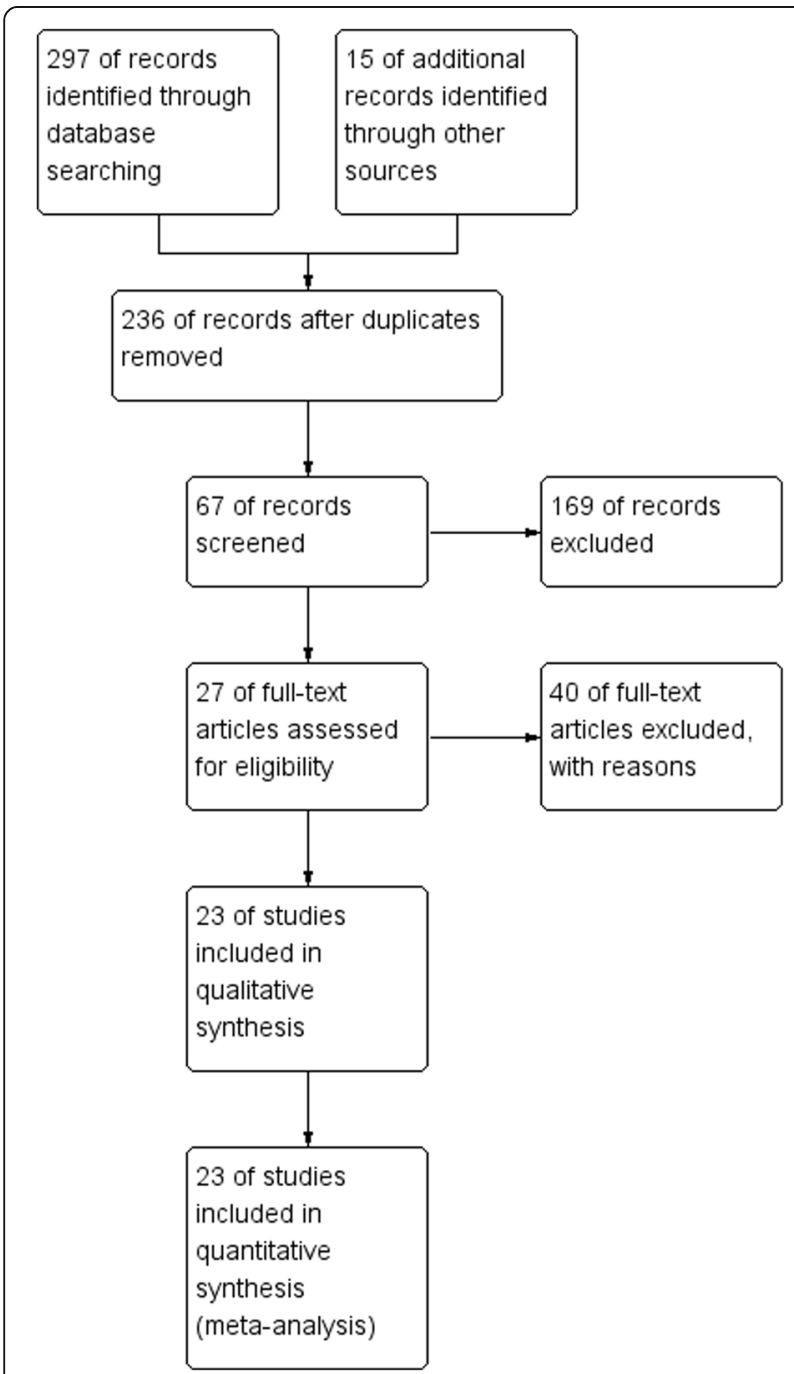

Fig. 1 PRISMA flowchart of the searched, identified, and included studies assessed for methodological quality, with 4 excluded because of poor methods conduct or reporting.

\section{Study characteristics}

Table 1 showed characteristics of included studies. Author, publication year, country, study design and methods, participants (\% male participants), case definition of technology exposure, exposure type of technology, age range (or average age) and sleep outcomes were listed.

Included studies were conducted in Europe $(n=9)$ (Arora et al., 2012; Arora et al., 2013; Arora et al., 2014; Bruni et al., 2015; Hysing et al., 2015; Van den Bulck, 2004; Lemola et al., 2014; Nuutinen et al., 2014; Punama-ki et al., 2006), East Asia $(n=10)$ (An et al., 2014; Cheung \& Wong, 2011; Choi et al., 2009; Liu et al., 2017; Mak et al., 2014; Park, 2014; Park \& Lee, 2017; Tan et al., 2016; Tamura et al., 2017; Kim et al., 2018), and West Asia $(n=4)$ (Fatih et al., 2013; Shochat et al., 2010; Sami et al., 2018; Hawi et al., 2018). Eight studies assessed the sleep duration of ETU and no excessive technology use (Arora et al., 2013; Arora et al., 2014; Fatih et al., 2013; Cheung \& Wong, 2011; Choi et al., 2009; Lemola et al., 2014; Shochat et al., 2010; Hawi et al., 2018). Three studies assessed the sleep onset latency (Arora et al., 2014; Cheung \& Wong, 2011; Shochat et al., 2010). Most of studies investigated association between the ETU and sleep problems.

\section{Sleep outcomes \\ Sleep duration}

Figure 2 shows the sleep duration of control and ETU groups. As can be seen, sleep duration of people in control condition is longer than that of ETU. The SMD is 0.25 , and $95 \% \mathrm{CI}$ is $(-0.37,-0.12)\left(P<.00001, \mathrm{I}^{2}=81 \%\right)$. The large heterogeneity was due to the study by Choi2009, which recruited people of average age of 16.7 \pm 1.0 . People's average age or age range in other studies were 13.9 \pm 2.0 of Arora2013, 11-13 of Arora2014, $16.04 \pm 1.02$ of Canan2013, $14.70 \pm 2.02$ of Cheung2010, $14.82 \pm 1.26$ of Lemola2014, $14.0 \pm 0.8$ of Shochat2010, $16.2 \pm 1.0$ of Hawi2018, respectively. After that study was excluded, the SMD was $-0.30(95 \% \mathrm{CI},-0.37$, $0.23)\left(P<.00001, \mathrm{I}^{2}=21 \%\right)$. Considering the age range of subjects was large, we divided them into two groups: younger adolescents (average age $\leq 14$ years) and older adolescents (average age $>14$ years). The SMD of younger group is -0.30 , and $95 \% \mathrm{CI}$ is $(-0.39,-0.20)\left(P=0.87, \mathrm{I}^{2}\right.$ $=0 \%$. The SMD of older group is -0.22 , and $95 \% \mathrm{CI}$ is $(-0.41,-0.02)\left(P<.00001, \mathrm{I}^{2}=87 \%\right)$.

\section{Sleep onset latency}

Three studies reported sleep onset latency of frequent use group and control group (Fig. 3). Sleep onset latency 


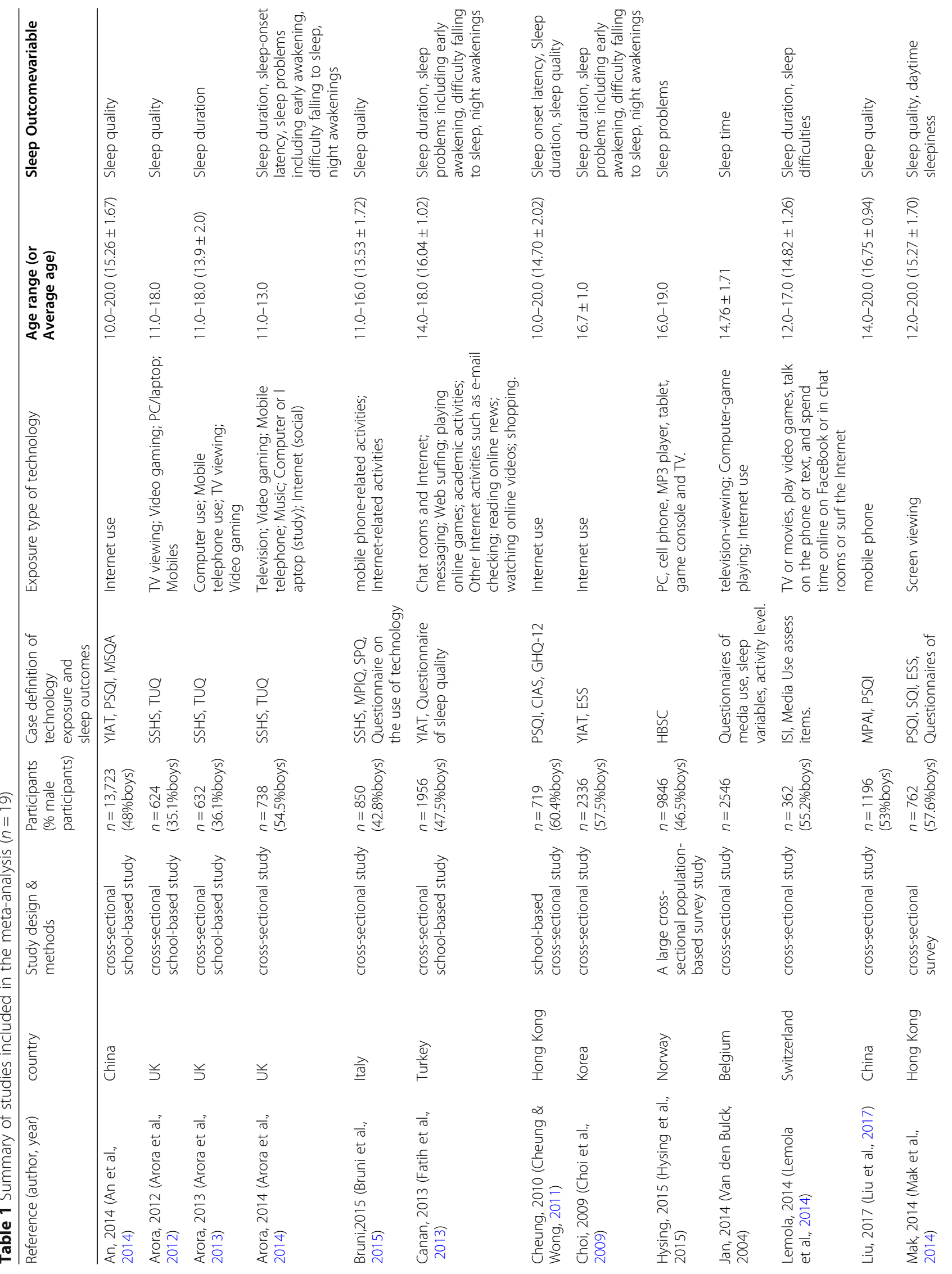




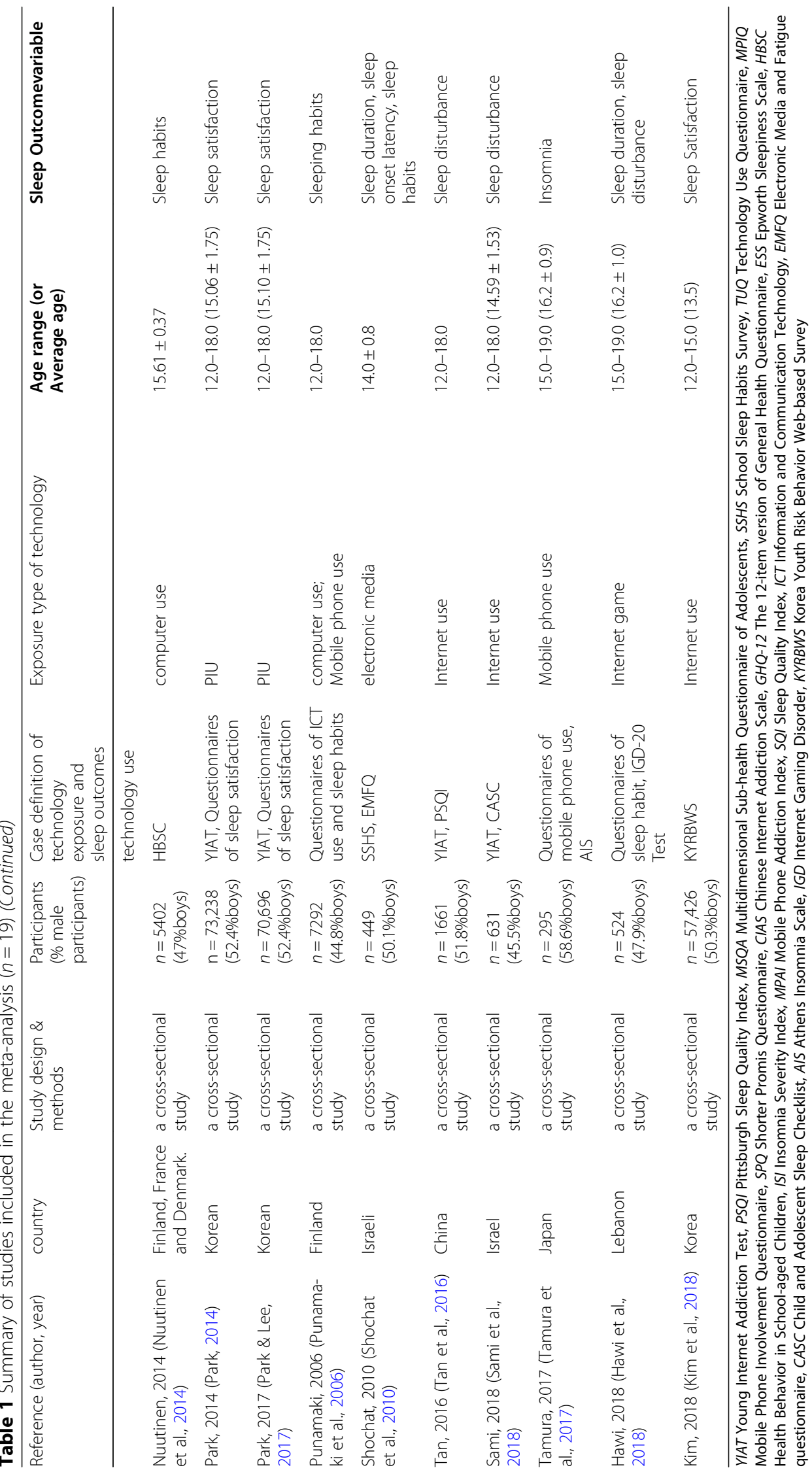


of people in control group is shorter than that of technology group $(P=0.05)$. The pooled SMD for sleep onset latency was $0.16(95 \% \mathrm{CI},-0.02-0.34) \quad\left(\mathrm{P}=0.05, \mathrm{I}^{2}=\right.$ $66 \%)$.

\section{Sleep problems}

There were data from 22 studies (An et al., 2014; Arora et al., 2012; Arora et al., 2014; Bruni et al., 2015; Fatih et al., 2013; Cheung \& Wong, 2011; Choi et al., 2009; Hysing et al., 2015; Van den Bulck, 2004; Lemola et al., 2014; Liu et al., 2017; Mak et al., 2014; Nuutinen et al., 2014; Park, 2014; Park \& Lee, 2017; Punama-ki et al., 2006; Shochat et al., 2010; Tan et al., 2016; Sami et al., 2018; Tamura et al., 2017; Hawi et al., 2018; Kim et al., 2018) that investigated association between the technology use and sleep problems (Fig. 4), including poor sleep quality (An et al., 2014; Arora et al., 2012; Bruni et al., 2015; Hysing et al., 2015; Lemola et al., 2014; Liu et al., 2017; Mak et al., 2014; Sami et al., 2018; Hawi et al., 2018), early awakenings (Arora et al., 2014; Fatih et al., 2013; Choi et al., 2009; Shochat et al., 2010), difficulty falling asleep (Arora et al., 2014; Fatih et al., 2013; Choi et al., 2009; Shochat et al., 2010), night awakenings (Arora et al., 2014; Fatih et al., 2013; Choi et al., 2009), less sleep quantity (Van den Bulck, 2004; Nuutinen et al., 2014; Park, 2014; Park \& Lee, 2017; Punama-ki et al., 2006; Shochat et al., 2010; Kim et al., 2018) and insomnia (Cheung \& Wong, 2011; Tan et al., 2016; Tamura et al., 2017). Three subgroups were classified by country. The OR of Asia subgroup was 1.55 (95\% CI, 1.48-1.62) $\left(P=0.24, \quad I^{2}=23 \%\right)$. The large heterogeneity of Asia-China subgroup was due to the study of An2014. After that study was excluded, the pooled OR was 1.10 (95\% CI, $1.05,1.15)\left(P=0.002, \mathrm{I}^{2}=79 \%\right)$. The large heterogeneity of Europe subgroup was due to the study of Jan2004, which recruited people of two average ages: first year: first year of secondary school (average age, 13 years); fourth year: fourth year of secondary school (average age, 16 years). After the study of Jan2004 was excluded, the OR was $1.24(95 \% \mathrm{CI}, 1.16,1.33)(P<.00001$, $\left.I^{2}=80 \%\right)$.

In Asia subgroup, dichotomous data were available from study of Canan2013 that investigated sleep problem including difficulty falling asleep, night awakenings, and early morning awakenings, the prevalences of which in no frequent use population were $37.9,36.0,16.1 \%$ respectively, and the prevalences of frequent use population were $44.9,44.1,19.0 \%$ respectively. In the study of Choi2009, Tamura2017 and Park2017, dichotomous data were also available, and there was an increased odds of sleep problems in people who had frequently used a technology device. In the study of Park2014, the associations between sleep satisfaction and problematic internet use was investigated [ $\beta$ coefficients (SE) were $0.47(0.03)]$, and odd ratio adjusted for age, sex, residing region, perceived academic performance, family economic status, parents' level of education, and body mass index. In the recent study of Sami2018, Hawi2018, and Kim2018, the ORs were $1.70,1.41$, and 1.72 respectively.

In Asia-China subgroup, the associations between technology use and sleep quality was reported by An2014 [ $\beta$ coefficients (SE) were $0.894 \quad(0.055)]$, Cheung2010 $[\beta$ coefficients (SE) were 0.08 (0.01)], Liu2017 [ $\beta$ coefficients (SE) were 0.34 $(0.1033)]$. In the study of Mak2014, the associations between technology use and sleep quality, and associations between technology use and excessive daytime sleepiness were accessed, and pooled OR was $1.14(95 \% \mathrm{CI}, 1.08,1.20)(P<0.001)$. In the study of Tan2016, the prevalence of problematic internet use was $17.2 \%$ among adolescents, with $40.0 \%$ of adolescents suffering from sleep disturbance, problematic internet use was found to be a significant predictor of sleep disturbance $(\beta=0.048, P<0.001)$.

In Europe subgroup, study of Arora2012 developed a model adjusted for age, sex, ethnicity, activity, school, snacking, depression, bedroom sharing and morningness-eveningness. After conducting pathway analysis, the impact of frequent technology use to sleep quality was evaluated $[\beta$ coefficients (SE) were $0.75(0.27)]$. In the study of Arora2014, the OR and 95\% confidence intervals for the multinomial regression between technologies and sleep parameters were 1.41 [1.18, 1.68]. Correlation between internet/mobile phone use and sleep problems was reported in the study of Bruni2015 ( $\beta=0.31, P<0.01)$. In the study of Hysing2015, the long sleep onset latency and sleep deficit were contribute to sleep problems, the pooled OR was 1.26 ( $95 \% \mathrm{CI}, 1.22$, 1.30) $(P<0.001)$. The effect of weekday and weekend technology use on sleep problems was investigated by Jan2004, the pooled OR was $1.07(95 \% \mathrm{CI}, 1.05,1.09)\left(P=0.16, \mathrm{I}^{2}=\right.$ $36 \%)$. In the study of Lemola2014, regression models revealed that electronic media use in bed before sleep was related to sleep difficulties $(\beta=0.21, P<0.001)$. In the study of Nuutinen2014, three countries' data were collected, the pooled OR was $1.22(95 \% \mathrm{CI}, 1.12,1.33)\left(P=0.46, \mathrm{I}^{2}=0 \%\right)$. Technology use including computer use and mobile phone use leaded to sleep problems in the study of Punamaki2006, the associations between technology use and sleep problems were reported in 12 and 14 years adolescents group and in 16 and 18 years adolescents group, the pooled OR was 1.24 (95\% CI, $1.14,1.35)\left(P=0.07, \mathrm{I}^{2}=53 \%\right)$. In the study of Shochat2010, technology use included internet use and television use, the pooled OR for sleep problems was 1.11 $(95 \% \mathrm{CI}, 1.07,1.15)\left(P=0.01 \mathrm{I}^{2}=54 \%\right)$.

\section{Discussion}

The present study sought to quantify the relationships between technology uses and sleep outcomes in adolescent 


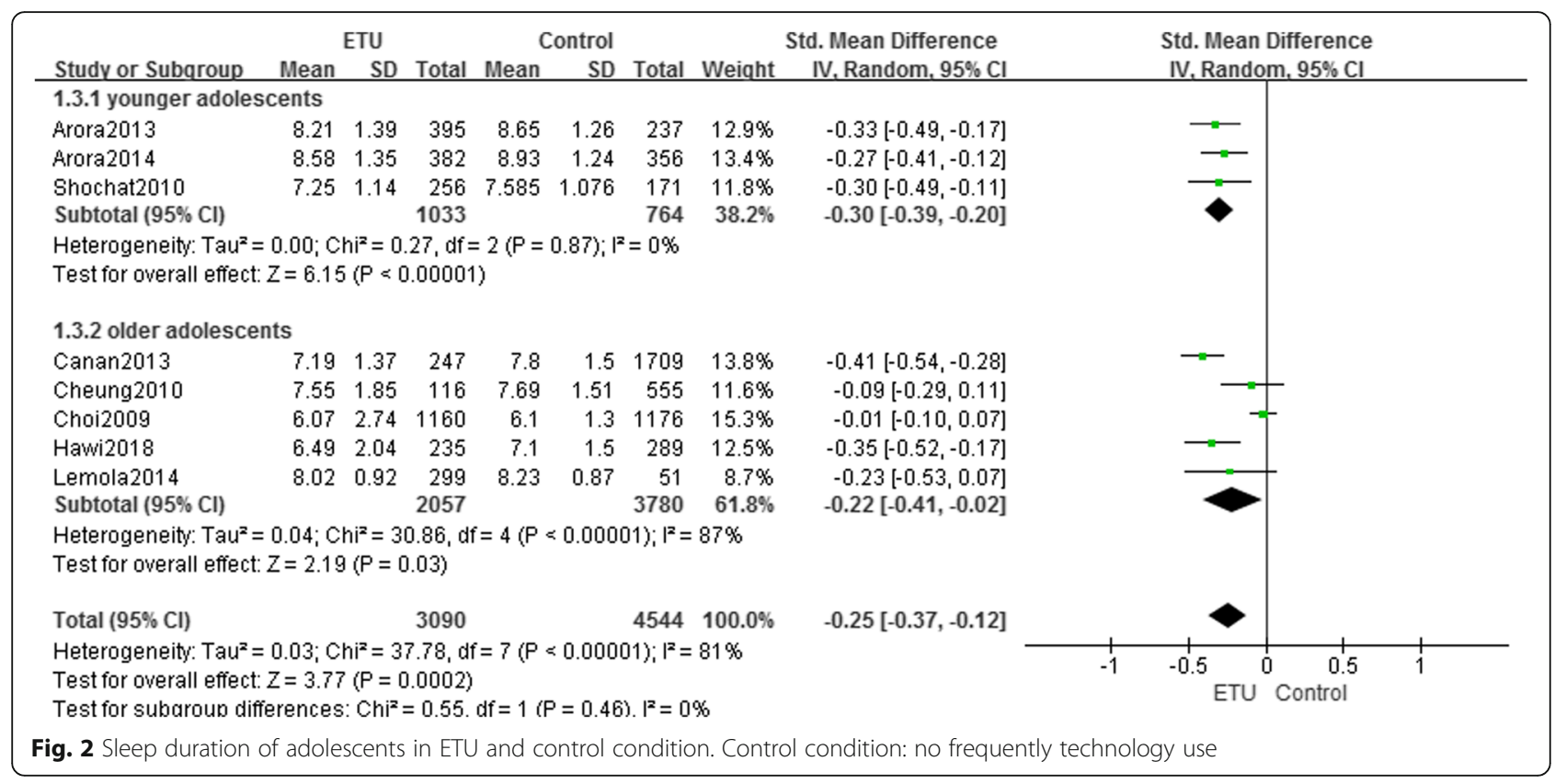

participants. The current meta-analysis ultimately contained results from 23 articles and involved combined sample sizes that ranged from 295 to 73,238 subjects, with 253,904 in total. This large sample could supply a considerable empirical basis for determining the contribution of technology overuses on poor sleep outcomes. In the first, ETU may disrupt the sleep by directly shortening or interrupting sleep time. In the second, the information on the Internet could be psychologically stimulating and affect the mood before sleep. Thirdly, the light emitted from the electronic screen may affect the circadian rhythm and physiological sleep (Cain \& Gradisar, 2010; Hale \& Guan, 2015; Chang et al., 2015). There may be other aspects of ETU that have not been found to damage sleep.

On the addictive aspect of technological devices or Internet use, young people may be more vulnerable than adults (Griffths \& Hunt, 1998). They may be more likely to be affected by internal conditions because their brain and mental state are in development. An interesting result of our meta-analysis was that studies in Asia, especially in Korea, reported larger effect sizes than Europe and Asia-China studies for outcome variables. This result was consistent with other findings (Winkler et al., 2013) indicating that culture-related differences in the study procedures as well as methodological differences may have caused this outcome. Meanwhile, sleep duration has significant differences among different age groups, while sleep onset latency does not (Ohayon et al., 2004). Our results indicated that ETU has a significant effect on sleep duration in adolescents over 14 years of age.

Although we have carried out a large number of sample analyses, our research still has some limitations. The limitations of research in this area include (1) the measurement error of self-reported data makes it difficult for us to determine the accuracy of the results, (2) in different articles the classification of the use of technology is different, and the definition of ETU is not the same (3) the speed of technology development is far beyond the

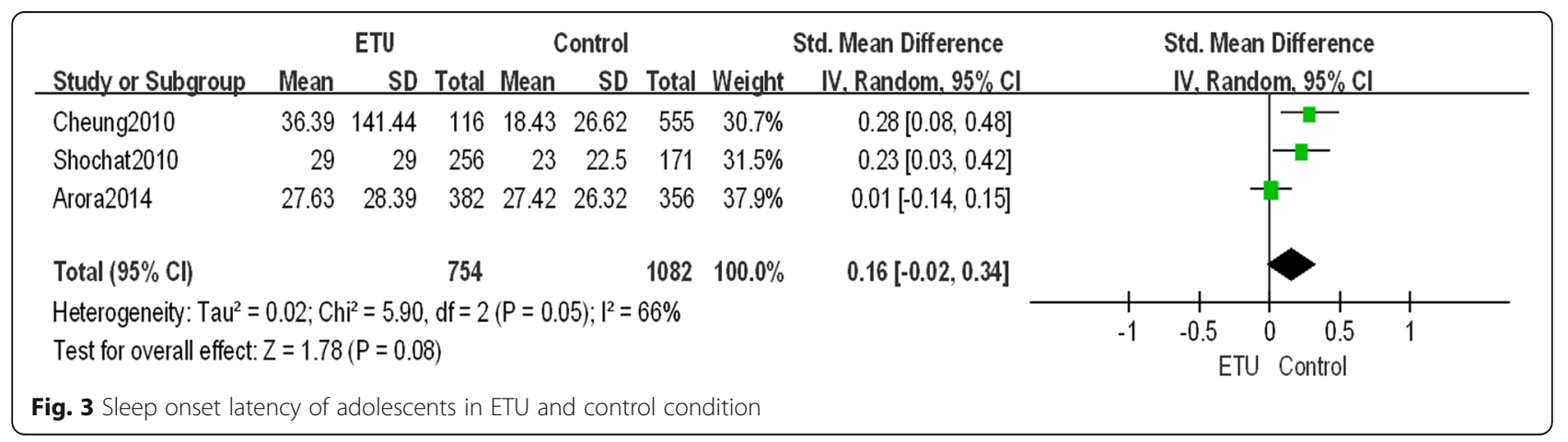




\begin{tabular}{|c|c|c|c|c|c|c|c|c|}
\hline \multirow{2}{*}{$\begin{array}{l}\text { Study or Subqroup } \\
\text { 1.2.1 Asia }\end{array}$} & log[Odds Ratio] & SE & \multicolumn{2}{|c|}{$\begin{array}{c}\text { Odds Ratio } \\
\text { Weight } \text { IV, Random, } 95 \% \mathrm{Cl} \\
\end{array}$} & \multicolumn{3}{|c|}{$\begin{array}{l}\text { Odds Ratio } \\
\text { IV, Random, } 95 \% \mathrm{Cl}\end{array}$} & \\
\hline & & & & & & & & \\
\hline Canan2013 & 0.2852 & 0.0831 & $4.9 \%$ & $1.33[1.13,1.57]$ & & & & \\
\hline Choi2009 & 0.5008 & 0.0695 & $5.3 \%$ & $1.65[1.44,1.89]$ & & & & \\
\hline Hawi2018 & 0.346 & 0.1052 & $4.3 \%$ & $1.41[1.15,1.74]$ & & & & \\
\hline Kim2018 & 0.5423 & 0.0836 & $4.9 \%$ & $1.72[1.46,2.03]$ & & & & \\
\hline Park2014 & 0.47 & 0.03 & $6.3 \%$ & $1.60[1.51,1.70]$ & & & & $\longrightarrow$ \\
\hline Park2017 & 0.4187 & 0.0205 & $6.4 \%$ & $1.52[1.46,1.58]$ & & & & $\rightarrow$ \\
\hline Sami2018 & 0.53 & 0.1362 & $3.4 \%$ & $1.70[1.30,2.22]$ & & & & \\
\hline Tamura2017 & 0.2624 & 0.4675 & $0.6 \%$ & $1.30[0.52,3.25]$ & & & & \\
\hline Subtotal $(95 \% \mathrm{Cl})$ & & & $36.1 \%$ & $1.55[1.48,1.62]$ & & & & \\
\hline \multicolumn{9}{|c|}{$\begin{array}{l}\text { Heterogeneity: } \text { Tau }^{2}=0.00 ; \mathrm{Chi}^{2}=9.12, \mathrm{df}=7(P=0.24) ;\left.\right|^{2}=23 \% \\
\text { Test for overall effect: } Z=19.25(P=0.00001)\end{array}$} \\
\hline \multicolumn{9}{|l|}{ 1.2.2 Asia-China } \\
\hline An2014 & 0.8936 & 0.0551 & $0.0 \%$ & $2.44[2.19,2.72]$ & & & & \\
\hline Cheung2010 & 0.08 & 0.01 & $6.5 \%$ & $1.08[1.06,1.10]$ & & & - & \\
\hline Liu2017 & 0.34 & 0.1033 & $4.3 \%$ & $1.40[1.15,1.72]$ & & & & \\
\hline Mak2014 & 0.131 & 0.0276 & $6.3 \%$ & $1.14[1.08,1.20]$ & & & & \\
\hline $\operatorname{Tan} 2016$ & 0.048 & 0.0146 & $6.5 \%$ & $1.05[1.02,1.08]$ & & & $\rightarrow$ & \\
\hline Subtotal $(95 \% \mathrm{Cl})$ & & & $23.6 \%$ & $1.10[1.05,1.15]$ & & & & \\
\hline \multirow{2}{*}{\multicolumn{9}{|c|}{$\begin{array}{l}\text { Heterogeneity: } \text { Tau }^{2}=0.00 ; \mathrm{Chi}^{2}=14.34, \mathrm{df}=3(\mathrm{P}=0.002) ; \mathrm{I}^{2}=79 \% \\
\text { Test for overall effect: } Z=4.06(\mathrm{P}<0.0001)\end{array}$}} \\
\hline & & & & & & & & \\
\hline \multicolumn{9}{|l|}{ 1.2.3 Europe } \\
\hline Arora2012 & 0.75 & 0.27 & $1.4 \%$ & $2.12[1.25,3.59]$ & & & & \\
\hline Arora2014 & 0.3436 & 0.0909 & $4.7 \%$ & $1.41[1.18,1.68]$ & & & & \\
\hline Bruni2015 & 0.31 & 0.1203 & $3.8 \%$ & $1.36[1.08,1.73]$ & & & & \\
\hline Hysing2015 & 0.2311 & 0.0165 & $6.5 \%$ & $1.26[1.22,1.30]$ & & & $\rightarrow$ & \\
\hline $\operatorname{Jan} 2004$ & 0.0677 & 0.0096 & $0.0 \%$ & $1.07[1.05,1.09]$ & & & & \\
\hline Lemola2014 & 0.21 & 0.0638 & $5.5 \%$ & $1.23[1.09,1.40]$ & & & & \\
\hline Nuutinen2014 & 0.1989 & 0.0436 & $6.0 \%$ & $1.22[1.12,1.33]$ & & & & \\
\hline Punamaki2006 & 0.2151 & 0.0429 & $6.0 \%$ & $1.24[1.14,1.35]$ & & & & \\
\hline Shochat 2010 & 0.1044 & 0.0187 & $6.4 \%$ & $1.11[1.07,1.15]$ & & & $\rightarrow$ & \\
\hline Subtotal $(95 \% \mathrm{Cl})$ & & & $40.3 \%$ & $1.24[1.16,1.33]$ & & & & \\
\hline \multicolumn{9}{|c|}{$\begin{array}{l}\text { Heterogeneity: } \text { Tau }^{2}=0.01 ; \mathrm{Chi}^{2}=35.63, \mathrm{df}=7(\mathrm{P}<0.00001) ; \mathrm{I}^{2}=80 \% \\
\text { Test for overall effect: } Z=6.39(P=0.00001)\end{array}$} \\
\hline Total $(95 \% \mathrm{Cl})$ & & & $100.0 \%$ & $1.33[1.24,1.43]$ & & & & \\
\hline \multicolumn{5}{|c|}{$\begin{array}{l}\text { Heterogeneity: } \text { Tau }^{2}=0.02 ; \mathrm{Chi}^{2}=491.68, \mathrm{df}=19(\mathrm{P}<0.00001) ; \mathrm{I}^{2}=96 \% \\
\text { Test for overall effect: } Z=7.78(\mathrm{P}<0.00001) \\
\text { Test for subaroun differences: } \mathrm{Ch}^{2}=116.00 . \mathrm{df}=2(\mathrm{P}<0.00001) . \mathrm{I}^{2}=98.3 \%\end{array}$} & 0.7 & $\begin{array}{ll}0.85 & 1 \\
\text { ETU }\end{array}$ & $\begin{array}{r}1.2 \\
\text { Control }\end{array}$ & 1.5 \\
\hline \multicolumn{9}{|c|}{ Fig. 4 Sleep problems of adolescents in in ETU and control condition } \\
\hline
\end{tabular}

speed of research (4) the design of observational studies has its inherent weaknesses.

Despite these limitations, the results of our study have several suggestions and implications. A detailed investigation of sleep duration and sleep onset latency in the ETU subjects was carried out. The results suggesting that the deleterious association between screen-based technology overuse and sleep is a major public health problem in adolescents. We suggest that if a young people who own technological devices has a sleep problem it is possible to consider whether or not it is related to ETU. During the clinical visits by health visitors or school nurses, we also encourage screening of adolescents to identify whether their sleep is associated with ETU, meanwhile, formulating a treatment plan for a specific situation.

\section{Conclusion}

In this study, we summarized published articles of various technology uses and sleep outcomes. We suggested that there is a significant association between ETU and poor sleep outcomes in adolescents. ETU has a significant effect on sleep duration in adolescents over 14 years of age, prolong the SOL of adolescents, and may lead to several sleep problems. We recommend that interventions to minimize technology use need to be developed and evaluated. Parents should understand the effects of 
the ETU factor on adolescents' sleep and pay more attention to their sleep and make children go to bed earlier, so as to ensure sleep time and improve sleep quality. In addition, teachers and doctors must help parents to raise awareness of the potential health hazard and to improve sleep hygiene.

\section{Abbreviations}

CIAS: Chinese Internet Addiction Scale; EMFQ: Electronic Media and Fatigue questionnaire; ESS: Epworth Sleepiness Scale; ETU: Excessive Technology Use; GHQ-12: The 12-item version of General Health Questionnaire; HBSC: Health Behavior in School-aged Children; ICT: Information and Communication Technology; ISI: Insomnia Severity Index; MPAI: Mobile Phone Addiction Index; MPIQ: Mobile Phone Involvement Questionnaire;

MSQA: Multidimensional Sub-health Questionnaire of Adolescents; PIU: Problematic Internet Use; PSQI: Pittsburgh Sleep Quality Index; SPQ: Shorter Promis Questionnaire; SQI: Sleep Quality Index; SSHS: School Sleep Habits Survey; TUQ: Technology Use Questionnaire; YIAT: Young Internet Addiction Test

\section{Funding}

This research was supported by Ningbo social development science and technology research project (grant No. 2014C50055).

\section{Availability of data and materials}

Data and material is available in Ningbo Key Laboratory of Sleep Medicine (Address: Zhuangyu South Road No.1, Zhenhai District, Ningbo City, Zhejiang Province, China, 315,201).

\section{Authors' contributions}

Study concept and design: XM. Acquisition, analysis, or interpretation of data: All authors. Drafting of the manuscript: XM. Statistical analysis: QZ, XL. Obtained funding: XW. Administrative, technical, or material support: ZH. Study supervision: XW and ZH. All authors read and approved the final manuscript.

\section{Ethics approval and consent to participate}

All analyses were based on previous published studies, thus no ethical approval and participate consent are required.

\section{Consent for publication}

Not applicable.

\section{Competing interests}

The authors declare that they have no competing interests.

\section{Publisher's Note}

Springer Nature remains neutral with regard to jurisdictional claims in published maps and institutional affiliations.

\section{Received: 25 April 2018 Accepted: 18 July 2018}

Published online: 01 August 2018

\section{References}

American Psychiatric Association. Diagnostic and Statistical Manual of Mental Disorders 5th edn., 2013, 51 (2): 4189-4189.

An J, Sun Y, Wan Y, Chen J, Wang X, Tao F. Associations between problematic internet use and adolescents' physical and psychological symptoms: possible role of sleep quality. J Addict Med. 2014;8:282-7.

Arora T, Hosseini-Araghi M, Bishop J, Yao GL, Thomas GN, Taheri S. The complexity of obesity in UK adolescents: relationships with quantity and type of technology, sleep duration and quality, academic performance and aspiration. Pediatric Obesity. 2012;8:358-66.

Arora T, Hussain S, Hubert Lam K-B, Lily Yao G, Neil Thomas G, Taheri S. Exploring the complex pathways among specific types of technology, self-reported sleep duration and body mass index in UK adolescents. Int J Obes. 2013; $37: 1254-60$.
Arora T, Emma B, Neil Thomas G, Taheri S. Associations between specific technologies and adolescent sleep quantity, sleep quality, and parasomnias. Sleep Med. 2014;15:240-7.

Bruni O, Sette S, Fontanesi L, Baiocco R, Laghi F, Baumgartner E. Technology use and sleep quality in preadolescence and adolescence. J Clin Sleep Med. 2015;11(12):1433-41.

Buysse DJ, Reynolds CF, Monk TH, Berman SR, Kupfer DJ. The Pittsburgh sleep quality index: a new instrument for psychiatric practice and research. Psychiatry Res. 1989;28:193-213.

Cain N, Gradisar M. Electronic media use and sleep in school-aged children and adolescents: a review. Sleep Med. 2010;11(8):735-42.

Carter B, Rees P, Hale L, et al. Association between portable screen-based media device access or use and sleep outcomes: a systematic review and Metaanalysis. JAMA Pediatr. 2016;170(12):1202-8.

Chang AM, Aeschbach D, Duffy JF, Czeisler CA. Evening use of light-emitting eReaders negatively affects sleep, circadian timing, and next-morning alertness. PNAS. 2015:112(4):1232-7.

Cheung LM, Wong WS. The effects of insomnia and internet addiction on depression in Hong Kong Chinese adolescents: an exploratory cross-sectional analysis. J. Sleep Res. 2011;20(2):311-7.

Choi K, Son H, Park M, Han J, Kim K, Lee B, Gwak H. Internet overuse and excessive daytime sleepiness in adolescents. Psychiatry Clin Neurosci. 2009; 63:455-62.

Dahl RE, Lewin DS. Pathways to adolescent health sleep regulation and behavior. J Adolesc Health. 2002;31:175-84.

Fatih CANAN, Osman YILDIRIM, Gjergji SINANI, Onder OZTURK, Tuba Yildirim USTUNEL, Ahmet ATAOGLU. Internet addiction and sleep disturbance symptoms among Turkish high school students. Sleep and Biological Rhythms. 2013;11:210-3.

Fredriksen K, Rhodes J, Reddy R, Way N. Sleepless in Chicago: tracking the effects of adolescent sleep loss during the middle school years. Child Dev. 2004;75:84-95.

Griffths MD, Hunt N. Dependence on computer games by adolescents. Psychol Rep. 1998:82:475-80.

Gruber R, Michaelsen S, Bergmame L, et al. Short sleep duration is associated with teacher-reported inattention and cognitive problems in healthy schoolaged children. Nat Sci Sleep. 2012;4:33.

Hale L, Guan S. Screen time and sleep among school-aged children and adolescents: a systematic literature review. Sleep Med Rev. 2015;21:50-8.

Hawi NS, Samaha M, Griffiths MD. Internet gaming disorder in Lebanon: relationships with age, sleep habits, and academic achievement. J Behav Addictions. 2018;7(1):70-8.

Hysing M, Pallesen S, Stormark KM, Jakobsen R, Lundervold AJ, Sivertsen B. Sleep and use of electronic devices in adolescence: results from a large population-based study. BMJ Open. 2015;5:e006748.

Kim SY, Kim M-S, Park B, Kim J-H, Choi HG. Lack of sleep is associated with internet use for leisure. PLoS One. 2018;13(1):e0191713.

Lemola S, Perkinson-Gloor N, Brand S, Dewald-Kaufmann JF, Grob A. Adolescents' electronic media use at night, sleep disturbance, and depressive symptoms in the smartphone age. J Youth Adolescence. 2014; https://doi.org/10.1007/ s10964-014-0176-X.

Liu Q-Q, Zhou Z-K, Yang X-J, Kong F-C, Niu G-F, Fan CY. Mobile phone addiction and sleep quality among Chinese adolescents: a moderated mediation model. Computers in Human Behavior. 2017; https://doi.org/10.1016/j.chb. 2017.02.042.

Mak YW, Wu CST, Hui DWS, Lam SP, Tse HY, Yu WY, Wong HT. Association between screen viewing duration and sleep duration, sleep quality, and excessive daytime sleepiness among adolescents in Hong Kong. Int. J. Environ. Res. Public Health. 2014;11:11201-19. https://doi.org/10.3390/ ijerph111111201

Munezawa T, Kaneita Y, Osaki Y, Kanda H, Minowa M, Suzuki K, et al. The association between use of mobile phones after lights out and sleep disturbances among Japanese adolescents: a nationwide cross-sectional survey. Sleep. 2011;34:1013-20.

National Sleep Foundation. Sleep in America Poll 200619 June 2012. Available from: http://sleepfoundation.org/sites/default/files/2006_summary_of_ findings.pdf.

National Sleep Foundation. Sleep in America Poll 2014: summary of findings. https://sleepfoundation.org/sites/default/files/2014-NSF-Sleep-inAmericapoll-summary-of-findings_FINAL-Updated-3-26-14-.pdf. Accessed 28 Sept 2016. 
Nuutinen T, Roos E, Ray C, Villberg J, Valimaa R, Rasmussen M, Holstein B, Godeau E, Beck F, Leger D, Tynjala J. Computer use, sleep duration and health symptoms: a cross-sectional study of 15 -year olds in three countries. Int J Public Health. 2014; https://doi.org/10.1007/s00038-014-0561-y.

Ohayon MM, Carskadon MA, Guilleminault C, Vitiello MV. Meta analysis of quantitative sleep parameters from childhood to old age in healthy individuals: developing normative sleep values across the human lifespan. SLEEP. 2004;27(7):1255-73.

Park S. Associations of physical activity with sleep satisfaction, perceived stress, and problematic internet use in Korean adolescents. Park BMC Public Health. 2014;14:1143.

Park S, Lee Y. Associations of body weight perception and weight control behaviors with problematic internet use among Korean adolescents. Psychiatry Res. 2017;251:275-80.

Punama-ki R-L, Wallenius M, Nyga rd C-H k, Saarni L, Rimpela A. Use of information and communication technology $(I C T)$ and perceived health in adolescence: the role of sleeping habits and waking-time tiredness. J Adolesc. 2006; https://doi.org/10.1016/j.adolescence.2006.07.004.

Rehbein F, Kleimann M, Mossle T. Prevalence and risk factors of video game dependency in adolescence: results of a German nationwide survey. Cyberpsychol Behav Soc Netw. 2010;13:269-77.

Sami H, Dannielle L, Lihi D, Elena S. The effect of sleep disturbances and internet addiction on suicidal ideation among adolescents in the presence of depressive symptoms. Psychiatry Research. 2018; https://doi.org/10.1016/j. psychres.2018.03.067.

Shochat T, Flint-Bretler O, Tzischinsky O. Sleep patterns, electronic media exposure and daytime sleep-related behaviours among Israeli adolescents. Acta Paediatr. 2010; https://doi.org/10.1111/j.1651-2227.2010.01821.x.

Stroup DF, Berlin JA, Morton SC, Olkin I, Williamson GD, Rennie D, Moher D, Becker BJ, Sipe TA, Thacker SB. Meta-analysis of observational studies in epidemiology: a proposal for reporting. JAMA. 2000;283(15):2008-12.

Tamura H, Nishida T, Tsuji A, Sakakibara H. Association between excessive use of mobile phone and insomnia and depression among Japanese adolescents. Int J Environ Res Public Health. 2017; https://doi.org/10.3390/ijerph14070701.

Tan Y, Chen Y, Lu Y, Li L. Exploring associations between problematic internet use, depressive symptoms and sleep disturbance among southern Chinese adolescents. Int J Environ Res Public Health. 2016;13: 313. https://doi.org/10.3390/ijerph13030313.

Tynjala J, Kannas L, Valimaa R. How young Europeans sleep. Health Educ Res. 1993:8:69-80

Van den Bulck J. Adolescent use of mobile phones for calling and for sending text messages after lights out: results from a prospective cohort study with a one-year follow-up. Sleep. 2007;30:1220-3.

Van den Bulck J. Television viewing, computer game playing, and internet use and self-reported time to bed and time out of bed in secondary-school children. SLEEP. 2004;27(1):101-4.

Weaver E, Gradisar M, Dohnt H, Lovato N, Douglas P. The effect of presleep videogame playing on adolescent sleep. J Clin Sleep Med. 2010:6:184-9.

Winkler A, Dörsing B, Rief W, Shen Y, Glombiewski JA. Treatment of internet addiction: a meta-analysis. Clin Psychol Rev. 2013:33:317-29.

Wolfson AR, Carskadon MA. Sleep schedules and daytime functioning in adolescents. Child Dev. 1998;69:875-87.

World Health Organization. The ICD-10 Classification of Mental and Behavioral Disorders: Clinical Description and Diagnostic Guidelines. The ICD-10. Geneva: World Health Organization; 1992.

Yen CF, Ko CH, Yen JY, Cheng CP. The multidimensional correlates associated with short nocturnal sleep duration and subjective insomnia among Taiwanese adolescents. Sleep. 2008;31:1515-25.

\section{Ready to submit your research? Choose BMC and benefit from:}

- fast, convenient online submission

- thorough peer review by experienced researchers in your field

- rapid publication on acceptance

- support for research data, including large and complex data types

- gold Open Access which fosters wider collaboration and increased citations

- maximum visibility for your research: over $100 \mathrm{M}$ website views per year

At $\mathrm{BMC}$, research is always in progress.

Learn more biomedcentral.com/submissions 